\title{
1 Sumerian in a Nutshell
}

\subsection{Introduction}

Sumerian was spoken in the southern part of ancient Mesopotamia, an area that roughly corresponds to today's Iraq. Sumerian is not genetically related to any known language. It is a mainly agglutinative language, characterized by ergativity with a split according to the semantic nature of the $\mathrm{NP}^{4}$ and to the tense and modality of the finite verb. It has a system of grammatical gender based on the distinction between human and non-human referents. It is a verb final language, ${ }^{5}$ and the order of words preceding the verb is determined by the information structure of the sentence. It is an extinct language. It can be studied today solely from written sources which were recorded using cuneiform writing, a mixed logographic-phonographic writing system. ${ }^{6}$ The first Sumerian texts that use enough phonographic signs to facilitate linguistic analysis date from around the middle of the 3rd millennium BC.

Contact between Sumerian and dialects of East Semitic is thought to have begun at least as early as the turn of the 4th to the 3rd millennium BC. The presumably widespread bilingualism resulted in similarities between the two languages on the level of phonology, morphology, syntax, and lexicon. From about the 24th century onwards one of the dialects of East Semitic, Akkadian, became the dominant language in the area with the consequence of asymmetrical bilingualism in which knowledge of Akkadian may have proved practical in more and more contexts. Akkadian as a vernacular replaced Sumerian during the first part of the second millennium BC. After around 1600 BC Sumerian remained to be taught and learnt only for the purposes of the cultic, literary and scholarly tradition. Sumerian texts were continued to be written until the 1st c. AD.

The mixed logographic-phonographic writing system that was used for recording Sumerian does an inexact job of representing its phonology and morphology. It reflects the morphophonological structure of Sumerian to varying extents in different periods (syllable final consonants, for example, are not written consistently until the beginning of the 2nd mill. BC). The morphophonological structure of Sumerian words must therefore be reconstructed by the interpretation of the graphemic sequence that

4 See Woods (2000, pp. 316-319).

5 A different word order in which the verb is followed by one of the nominal constituents of the clause is attested only in literary texts; see, for example, ex. (106i) below.

6 For the writing system see Civil (1973), Krebernik and Nissen (1994) or Cooper (1996).

(c))BY-NC-ND (c) 2014 Gábor Zólyomi

This work is licensed under the Creative Commons Attribution-NonCommercial-NoDerivs 3.0 License. 
includes setting up correspondences between sequences of graphemes and sequences of morphemes. This interpretation is necessarily subjective to some extent, and reflects the grammatical model of the interpreter; the object of linguistic description, however, must be the reconstructed sequence of morphemes, and not that of graphemes.

Accordingly, in the Sumerian examples used in this grammar, the first line represents the utterance in standard graphemic transliteration; the second, a segmentation into morphemes (reconstructed by interpreting the sequence of graphemes); the third, a morpheme-by-morpheme glossing; and the fourth, a translation. In the graphemic transliteration subscript numerals distinguish homophonic graphemes; graphemes that constitute a word are linked by hyphens; superscript graphemes are semantic classifiers. In the morphemic segmentation and in the glosses the sign "=" links enclitics to their hosts. Two special characters are used in transliterating Sumerian: $\mathfrak{\eta}$ (pronounced as the last consonant in sing) and š (as the first consonant in ship).

A particular feature of the writing system, often misunderstood by non-specialists, is the use of the sequence of $\mathrm{C}$ (onsonant)V(owel) and VC graphemes for writing a closed syllable /cvc/. As the number of phonographic signs with a CVC reading was limited, the ancient scribes started to use VC signs for writing the last consonant of closed syllables. So, for example, the syllable /men/ was written as me-en or $_{3}$ me-en from about the end of the 3rd millennium BC. The vowel of the first and the second sign was the same, and the writing stood not for /me'en/ but for the closed syllable/men/; the second sign was used only for its consonant, as their was no $\mathrm{C}$ sign in the writing system.

The linguistic evidence used in this work consists solely of ancient written documents. The number of Sumerian texts is estimated to be more than $100.000 .^{7}$ Unfortunately only a very small portion of this relatively vast corpus may be used for the purpose of linguistic description. Probably around $90 \%$ of these texts are administrative documents whose main purpose was not to record linguistic utterances but a set of organized data. Accordingly, administrative documents are used in this work only sporadically.

The linguistic description of this work relies mainly on four broad categories of texts: literary texts, royal inscriptions, legal documents, and administrative letters. In the following short survey I will evaluate these categories from the point of view of their usefulness to grammatical research on information structure in Sumerian.

A substantial part of the linguistic evidence comes from literary texts dated to the first part of the 2nd millennium BC. These texts written on clay tablets were used to teach apprentice scribes to speak and write Sumerian in scribal schools and training workshops at an advanced stage of their curriculum (Tinney, 1999; Veldhuis, 1997).

7 For a recent estimation of the size of the cuneiform corpus, see Streck (2010). The Cuneiform Digital Library Initiative project (CDLI, http://cdli.ucla.edu) provides a comprehensive catalogue of all cuneiform texts; their catalogue numbers, the P-numbers, are also referred to in this work, in the heading of the examples. 
Most of the literary texts we have are their discarded exercises. They typically have more than one manuscript. Literary texts are, as a rule, quoted after their edition by the Electronic Texts Corpus of Sumerian Literary Texts project (http://etcsl.orinst. ox.ac.uk); the heading of each literary example contains the catalogue number of the project. The text editions of ETCSL are based on composite texts which conceal a host of ad hoc decisions made by the editors. The composite texts are compiled from individual manuscripts, which exhibit a great deal of variation, especially at the morphological level. ${ }^{8}$ Consequently, whenever an example from a literary text showed a variant that may have influenced my argument, I quoted the text of the individual manuscript instead of the composite text.

The most frequently quoted literary text in this work, however, is not the product of the scribal schools of the 2nd millennium BC. It was written earlier, during the 22nd century of the 3rd millennium BC. This text, referred to as the Cylinders of Gudea, was inscribed on two clay cylinders excavated in Lagash. It is the longest Sumerian literary composition (1363 lines long), known only in one copy. It relates how Gudea, ruler of the city state Lagash, rebuilds the temple of Ningirsu, the tutelary deity of Lagash. It comes from a period in which Sumerian is thought to have still been a spoken language in the Southern parts of Mesopotamia.

The literary texts use a formal, aesthetically and rhetorically stylised register far from the vernacular. This is, however, the most diverse category which contains both hymnic and narrative texts. Importantly for the research on information structure in Sumerian, these texts occasionally contain dialogues.

Another often cited group of texts is the corpus of so called royal inscriptions. These are votive or commemorative texts recording events (e.g. building or ritual activities, military conflicts, etc.) considered important by members of the political elite. They range from simple one sentence dedicatory inscriptions to complex accounts of military conflicts between neighboring city-states or states. They were as a rule written on objects that were meant to be placed in a sacred space (e.g. before a deity) or to be part of a religious building (bricks, vessels, mace-heads, clay cones, stelae, statues etc.). ${ }^{9}$ The royal inscriptions also use a formal register. Longer narrative texts occasionally include quotations of direct speech.

Both literary texts and royal inscriptions assume the existence of a narrator whose point of view has an impact on the way the text is formulated, which in turn may prove useful for an investigation that aims to reconstruct the information structure of Sumerian sentences.

8 See Delnero (2012, pp. 1-4) on composite texts of Sumerian literary compositions from the 2nd millennium BC. For a selection of translations from the ETCSL corpus with introductions, see Black et al. (2004). 9 Most of the Sumerian royal inscriptions are now available online in transliteration and in English and Hungarian translations, morphologically and grammatically analyzed on the website of the Electronic Text Corpus of Sumerian Royal Inscriptions project: http://oracc.museum.upenn.edu/etcsri. 
Legal texts are another important group of texts relied on in this work. The legal texts utilized here are typically trial records made for the central administration; they date to the end of the 3rd millennium BC. These texts often contain direct or indirect quotations from the litigants, which may reflect vernacular usage. ${ }^{10}$

The letters used here usually concern no personal matters, but issues arising from the management of the administration. Nevertheless, these texts are written communication for an addressee, consequently, their text is manipulated to express the sender's intentions and points of view.

\subsection{The Sumerian Nominal and Verbal Template ${ }^{11}$}

The Sumerian noun phrase consists of five structural positions (see Table 1.1 below). P1 and P2 may be occupied by a variety of structural units. P3 may be filled either with a noun phrase in the genitive or with an enclitic possessive pronoun. The possessive pronoun in $\mathrm{P} 3$ and the elements occurring in $\mathrm{P} 4$ and $\mathrm{P} 5$ are enclitics, i.e. affixes being added to phrases but not to lexical heads. ${ }^{12}$

Tab. 1.1: The Sumerian nominal template

\begin{tabular}{lllll}
\hline 1. & 2. & 3. & 4. & 5. \\
\hline Head & Modifier & Possessor & Plural-Marker & Case-Marker \\
\hline
\end{tabular}

This apparently simple structure may produce very complex constructions, primarily due to the range of structural units that may occur in P3. This position, that of the possessor, may be occupied by two kinds of elements: by an enclitic possessive pronoun (as in ex. [1]), or by a NP in the genitive case (as in ex. [2]).

(1) Amar-Suena 33 (RIME 3/2.1.3.3) (Nippur, 21st c.) (P226441) ${ }^{13}$

lugal-ni-ir

${ }_{\mathrm{p} 1}$ lugal ${ }_{\mathrm{p} 3} \mathrm{ani}{ }_{\mathrm{p} 5} \mathrm{ra}$

${ }_{\mathrm{P} 1} \mathrm{king}={ }_{\mathrm{P} 3} \mathrm{POSS} .3 \mathrm{SG}={ }_{\mathrm{P} 5}$ DAT. $\mathrm{H}$

"for his master"

10 The most important work that edits and discusses this group of texts is still Falkenstein (1956a, 1956b).

11 This description is an updated and abridged version of Zólyomi (2007). Other recent grammatical descriptions of Sumerian are Edzard (2003), Michalowski (2004), Rubio (2007) and Jagersma (2010).

12 On clitics in Sumerian, see Zólyomi (1996, esp. pp. 34-36).

13 P-numbers refer to the catalogue-numbers of the Cuneiform Digital Library Initiative Project (http://www.cdli.ucla.edu). 
(2) Ur-Bau 13 (RIME 3/1.6.1) (Lagash, 22nd c.) (P231808)

dumu an-na-ra

${ }_{\mathrm{P} 1}$ dumu ${ }_{\mathrm{P} 3}\left[\mathrm{P}_{\mathrm{P} 1} \mathrm{an}{ }_{\mathrm{P} 5} \mathrm{ak}\right]={ }_{\mathrm{P} 5} \mathrm{ra}$

${ }_{\mathrm{P} 1}$ child ${ }_{\mathrm{P} 3}\left[{ }_{\mathrm{P} 1} \mathrm{DN}={ }_{\mathrm{P} 5} \mathrm{GEN}\right]={ }_{\mathrm{P} 5} \mathrm{DAT} . \mathrm{H}$

"for the child of the god An"

The NP occupying P3 may have elements in up to four of its five positions, and then there may be four structural units between the head (P1) and the case-marker (P5) of the main NP as in ex. (3):

(3) CUSAS 17, 13 3:8 (?, cca. 23th c.) (P251599)

nam-til ${ }_{3}$ šeš-a-ne-ne

${ }_{P 1}$ namtil ${ }_{P 3}\left[{ }_{p 1} \check{\text { seš }}={ }_{P 3}\right.$ ani $=_{P 4}$ ene $=_{P 5}$ ak $]={ }_{P 5} \varnothing$

life $\quad{ }_{\mathrm{P} 3}\left[{ }_{\mathrm{P} 1}\right.$ brother $\left.{ }_{\mathrm{P} 3} 3 \mathrm{SG} . \mathrm{POSS}={ }_{\mathrm{P} 4} \mathrm{PL}={ }_{\mathrm{P} 5} \mathrm{GEN}\right]={ }_{\mathrm{P} 5} \mathrm{ABS}$

"the well-being of his brothers"

In exx. (4) and (5) below, the NP occupying P3 contains yet another NP in its P3. In ex.

(5) the embedded NP is an appositional construction.

(4) Iri-kagina 1 3:18 (RIME1.9.9.1) (Lagash, 24th c.) (P222607)

sipad udu siki-ka-ke-ne

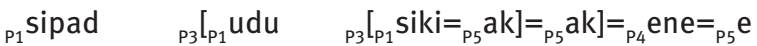

${ }_{\mathrm{P} 1}$ shepherd ${ }_{\mathrm{P} 3}\left[\mathrm{P}_{\mathrm{P} 1}\right.$ sheep ${ }_{\mathrm{P} 3}\left[\mathrm{P}_{\mathrm{P} 1}\right.$ wool $\left.\left.=_{\mathrm{P} 5} \mathrm{GEN}\right]=_{\mathrm{P} 5} \mathrm{GEN}\right]={ }_{\mathrm{P} 4} \mathrm{PL}={ }_{\mathrm{P} 5} \mathrm{ERG}$

"the shepherds of sheep of wool (= wool-bearing sheep)"

(5) Shulgi 2046 1'-3’ (RIME 3/2.1.2.2046) (Ur, 21st c.) (P226193)

nam-til $_{3}$ dšul-gi dinir kalam-ma-na-ka-še ${ }_{3}$

${ }_{P 1}$ namtil ${ }_{P 3} L_{P 1}$ šulgir dinir $\left.{ }_{P 3}\left[{ }_{P 1} k a l a m={ }_{P 3} a n i={ }_{P 5} a k\right]={ }_{P 5} a k\right]={ }_{P 5}$ še

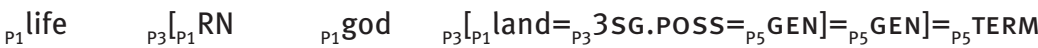

"for the well-being of Shulgi, the protective god of his land"

As the elements in $\mathrm{P} 4, \mathrm{P} 5$, and the possessive pronoun in $\mathrm{P} 3$ are enclitics attaching to the final word-level constituent of the NP, all these elements cumulate at the right end of the phrase in simple and double genitive constructions like (3), (4) and (5).

The nominal slot P5 of the Sumerian noun phrase accommodates the case-markers. Ten enclitic case-markers can be distinguished in Sumerian: $=/ \varnothing /,=/ \mathbf{e} /,=/\left(\mathbf{( '}^{\prime}\right) \mathbf{a} /{ }^{14}$, $=/ \mathbf{r a} /,=/ \mathbf{t a} /,=/ \mathbf{d a} /,=/ \mathbf{s ̌ e} /,=/ \mathbf{a k} /,=/ \mathbf{g i n} /$, and =/eš/. The case-markers are enclitics that function to distinguish cases. In Sumerian cases are distinguished, however, not

14 The glottal stop at the beginning of this case-marker was gradually lost during the second half of the 3rd millennium BC; see Jagersma (2010, pp. 28-41). 
solely by nominal case-markers, the verbal affixes also play an essential role in the identification of cases. ${ }^{15}$ Three of the nominal case-markers (=/ra/, =/(')a/, and =/e/), and one of the verbal affixes (/i/ in S10) are used as markers of more than one case. On the basis of correspondences between nominal case-markers and verbal affixes, 12 cases can be distinguished in Sumerian:

Tab. 1.2: The Sumerian case-system

\begin{tabular}{|c|c|c|c|}
\hline \multirow[t]{2}{*}{ case } & \multicolumn{2}{|c|}{ nominal case-marker } & \multirow[t]{2}{*}{ verbal affix } \\
\hline & human & non-human & \\
\hline ergative & $=/ \mathrm{e} /$ & $=/ \mathrm{e} /$ & $\begin{array}{l}\text { final pronominal prefix (S11) }{ }^{16} \text { and pro- } \\
\text { nominal suffix (S14) }\end{array}$ \\
\hline absolutive & $=\mid \varnothing /$ & $=\mid \varnothing /$ & $\begin{array}{l}\text { final pronominal prefix (S11) and prono- } \\
\text { minal suffix (S14) }\end{array}$ \\
\hline \multicolumn{4}{|c|}{ dimensional cases } \\
\hline $\begin{array}{l}\text { dative } \\
\text { comitative } \\
\text { ablative } \\
\text { terminative } \\
\text { locative1 } \\
\text { locative2 } \\
\text { locative3 }\end{array}$ & $\begin{array}{l}=/ \mathrm{ra} / \\
=/ \mathrm{da} / \\
- \\
=/ \mathrm{še} / \\
- \\
=/ \mathrm{ra} / \\
=/ \mathrm{ra} /\end{array}$ & $\begin{array}{l}=/ \mathrm{e} / \\
=/ \mathrm{da} / \\
=/ \mathrm{ta} / \\
=/ \mathrm{s} \mathrm{e} / \\
=/\left({ }^{\prime}\right) \mathrm{a} / \\
=/\left({ }^{\prime}\right) \mathrm{a} / \\
=/ \mathrm{e} /\end{array}$ & $\begin{array}{l}/ \mathrm{a} / \text { (S7) } \\
/ \mathrm{da} /(\mathrm{S} 8) \\
/ \mathrm{ta} /(\mathrm{S} 9) \\
/ \mathrm{s} \mathrm{i} /(\mathrm{S} 9) \\
/ \mathrm{ni} /(\mathrm{S} 10) \\
/ \mathrm{i} /(\mathrm{S} 10) \\
/ \mathrm{i} /(\mathrm{S} 10)\end{array}$ \\
\hline \multicolumn{4}{|l|}{ other cases } \\
\hline $\begin{array}{l}\text { genitive } \\
\text { equative } \\
\text { adverbiative }^{17}\end{array}$ & $\begin{array}{l}=/ \mathrm{ak} / \\
=/ \mathrm{gin} / \\
=/ \mathrm{eš} /\end{array}$ & $\begin{array}{l}=/ \mathrm{ak} / \\
=/ \mathrm{gin} / \\
=/ \mathrm{eš} /\end{array}$ & $\begin{array}{l}- \\
- \\
-\end{array}$ \\
\hline
\end{tabular}

The twelve cases can be classified into three groups: i) ergative and absolutive, encoders of $\mathrm{A}$ (gent), S(ubject) and $\mathrm{P}$ (atient), the primary syntactic functions; ii) dimensional cases; iii) cases that relate to no corresponding verbal affixes.

15 In the most widely used grammars of Sumerian (e.g., Thomsen [1984], Edzard [2003]) cases are identified according to their nominal case-markers. The system used in this work identifies the cases on the basis both of their nominal and verbal marking, which results in a considerably different system. For a description of the Sumerian cases in these terms, see Zólyomi (2010).

16 Verbal structural positions will be referred to as "slots" (=S) throughout this work to distinguish them form the structural positions of the noun phrase, referred to as "positions" $(=\mathrm{P})$.

17 For this case, which is not recognized by older grammars, see Attinger (1993, p. 253), Jagersma (2010, pp. 189-191) and Meyer-Laurin (2012). 
Table 1.3 below summarizes the local meanings of the Sumerian dimensional cases except for the dative:

Tab. 1.3: The local meanings of the dimensional cases of S7-10

\begin{tabular}{|c|c|c|c|c|}
\hline & & & location "at" destination "to" & source "from" \\
\hline \multirow{3}{*}{$\begin{array}{l}\text { always with } \\
\text { contact (S10) }\end{array}$} & interior & & locative1 & - \\
\hline & ovtorior & horizontal (“above") & locative2 & - \\
\hline & CALCTU & non-horizontal ("beside") & locative3 & - \\
\hline $\begin{array}{l}\text { neutral to } \\
\text { contact (S7-9) }\end{array}$ & adjacent & & terminative & ablative \\
\hline
\end{tabular}

Finite verbal forms in Sumerian are distinguished by the large number of affixes which can be attached to a verbal stem. The morphological segmentation and glossing of the Sumerian examples in this work are based on the assumption that the Sumerian finite verbal form exhibits a template morphology, and the affixes and the verbal stem can be arranged into fifteen structural positions or slots. Table 1.4 below summarizes the analysis that underlies the glossing of the examples. ${ }^{18}$

Tab. 1.4: Sumerian verbal template of finite verbs

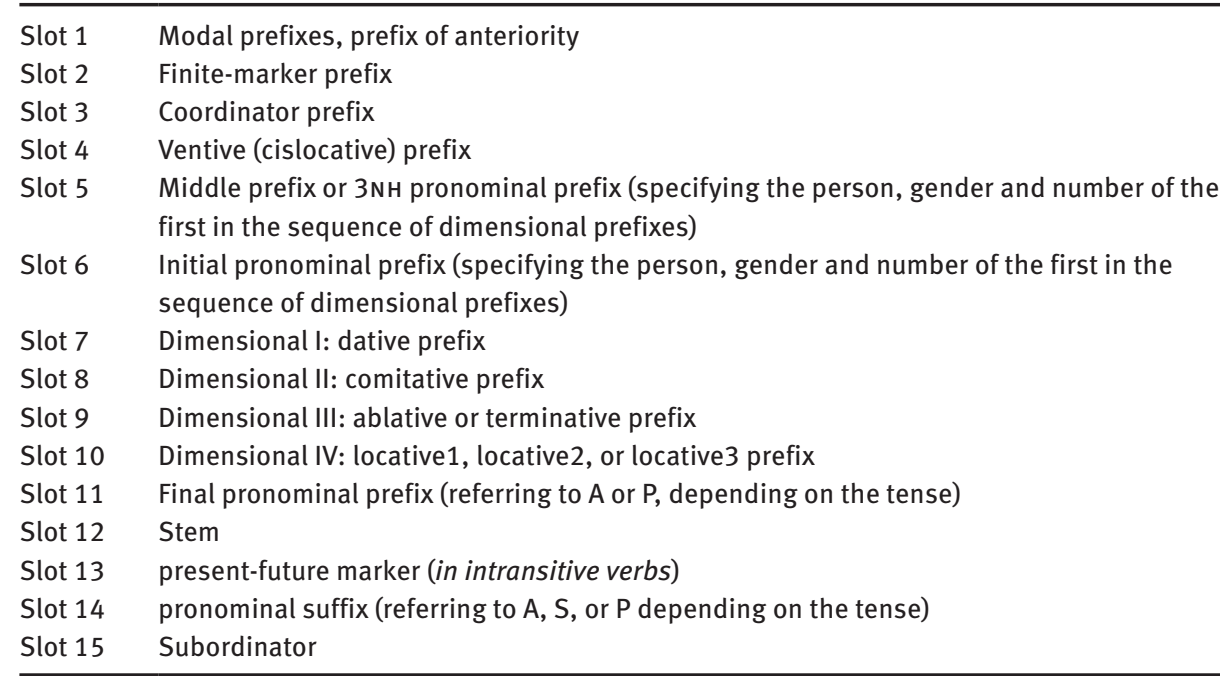

18 Template morphology is understood as a system "in which inflectional affixes are apparently organized into a number of position classes such that the members of any given class are mutually exclusive but occupy the same sequential position, or slot, relative to members of other classes within a given word form” (Stump, 2001, p. 33). 
Unlike in German or English, where among the participants of a verb only the subject is cross-referenced with an affix on the verbal form, Sumerian verbal forms may crossreference up to four participants of the verb.

The Agent, the Subject and the Patient are cross-referenced with pronominal affixes in S11 and S14. The syntactic function of their referents is indicated mainly by their position, so, e.g., in the present-future conjugation the pronominal suffix in S13 cross-references A and S, while the final pronominal prefix in S11 cross-references P.

The affixes of S5-10 are involved in the verbal cross-referencing of participants other than the Agent, Subject and Patient. These participants may be cross-referenced either by a composite or by a simple dimensional prefix.

A composite dimensional prefix is composed of i) a pronominal prefix and ii) a dimensional prefix. The former specifies the person, gender, and number, while the latter identifies the syntactic function of the prefix's referent. In ex. (6) below, the indirect object of the verb "to give" is in the dative case. In the verbal prefix-chain this participant is referred to by a composite dative prefix that consists of an initial pronominal prefix /nn/ in S6 and a dative prefix /a/ in S7 (both in bold).

(6) Enmerkar and the Lord of Aratta 420 (ETCSL 1.8.2.3)

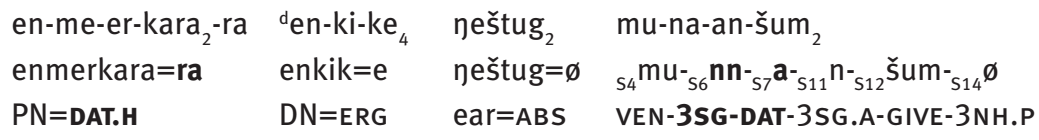

"The god Enki gave wisdom to Enmerkara."

A simple dimensional verbal prefix consists only of a dimensional prefix without a pronominal prefix. The occurrence of simple dimensional prefixes follows from the structure of the verbal prefix-chain: there is only one pronominal slot, S6, before the dimensional prefixes ${ }^{19}$ (this rule, however, is valid only with some qualifications, for which see below). So, if, for example, the prefix-chain contains a dative prefix in S7, then any dimensional prefix following the dative prefix must occur as a simple dimensional prefix, i.e., without a pronominal prefix. In ex. (7) below, for example, the locative2 prefix in S10 (in bold) occurs as a simple prefix, because it is preceded by a composite dative prefix.

(7) MVN 8, 2215 (Drehem, 21st c.) (P115611)

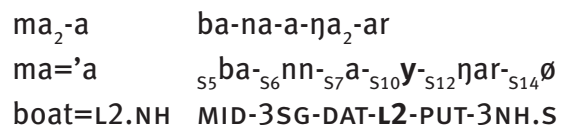

"(Various animals) were put on the boat for him."

19 This rule, which has fundamental importance for the proper analysis of the verbal prefix-chain, has been explicitly formulated by Joachim Krecher (1985, p. 133, note 1) for the first time; see also Attinger (1993, p. 206, §134 R1). 
In contrast, the locative 2 prefix occurs as a composite dimensional prefix in ex. (8) below. It consists of an initial pronominal prefix /nn/ in S6 and a locative prefix /i/ in S10 (both in bold). In this example the locative2 prefix in S10 is the first dimensional prefix: it is not preceded by any other dimensional prefix, and there is no other morpheme between it and the initial pronominal prefix in S6. Consequently, the initial pronominal prefix specifies the person, gender and number of the verbal participant in the locative2 case.

(8) En-metena $16: 21-23$ (RIME 1.9.5.1) (Lagash, 24th c.)

$$
\begin{aligned}
& \text { dnin-nir }{ }_{2} \text {-su-ke }{ }_{4} \text {, sa-šuš-gal-ni, } \quad u_{3} \text {-ni-šuš }
\end{aligned}
$$

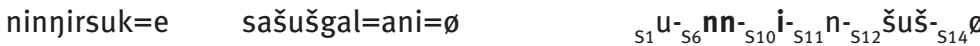

$$
\begin{aligned}
& \text { DN=ERG battle.net=3SG.POSS=ABS ANT-3SG-L2-3SG.A-COVER-3NH.P } \\
& \text { "After Ningirsu cast on him his great battle-net, ...." }
\end{aligned}
$$

It follows from the above description that the dative prefix always occurs as a composite prefix, as its slot (S7) is the nearest to the slot of the initial pronominal prefix (S6). Other dimensional prefixes may have either a composite or simple form. Simple dimensional prefixes always refer to a 3rd ps. non-human participant. ${ }^{20}$

The pronominal prefix of a composite dimensional prefix is as a rule a morpheme in S6. There exist, however, two exceptions to this rule: i) 3rd ps. non-human pronouns are expressed by an allomorph of the middle prefix in S5, as in exx. (9) and (12) below; ${ }^{21}$ ii) with some of the cases expressing motion towards an entity (dative, locative2), the 1st ps. sg. pronoun is expressed by an allomorph of the ventive (cislocative) prefix in S4.

(9) Gudea Statue B 4:7-9 (Lagash, 21st c.) (P232275)

$$
\begin{aligned}
& \mathrm{e}_{2} \quad{ }^{\mathrm{d}} \text { nin-nir }{ }_{2} \text {-su-ka, eridug }{ }^{\mathrm{ki}} \text {-gin }{ }_{7} \text {, } \\
& \text { e ninnirsuk }=a k=\varnothing \text { eridug }=\text { gin } \\
& \text { house } \quad \mathrm{DN}=\mathrm{GEN}=\mathrm{ABS} \quad \mathrm{GN}=\mathrm{EQU} \\
& \text { ki sikil-la } \quad \mathrm{bi}_{2}-\mathrm{du}_{3}
\end{aligned}
$$

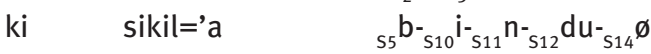

$$
\begin{aligned}
& \text { place pure }=\text { L2.NH 3NH-L2-3SG.A-build-3NH.P }
\end{aligned}
$$

"He built the temple of Ningirsu in a place as pure as the city of Eridug."

20 This statement was also part of Krecher's original observation about the structure of the verbal prefix-chain.

21 This morpheme will be glossed as 3NH and not as MID when it functions as a 3rd person nonhuman pronoun. 
In ex. (10) below, the ventive prefix in S4 precedes the dative prefix in S6, and the two morphemes form a composite dimensional prefix with a 1st ps. sg. referent; see also ex. (18) below.

(10) The victory of Utu-hegal 29 (ETCSL 2.1.6)

\begin{tabular}{|c|c|c|}
\hline $\begin{array}{l}\text { gu-ti-um }{ }^{\mathrm{ki}} \\
\text { gutium }=\varnothing \\
\text { GN=ABS }\end{array}$ & $\begin{array}{l}{ }^{\mathrm{d} e n-l i l_{2}} \text {-le } \\
\text { enlil=e } \\
\text { DN=ERG }\end{array}$ & $\begin{array}{l}\text { ma-an-šum }{ }_{2} \\
{ }_{s 4} \mathrm{~m}_{\text {s7 }} \mathrm{a}-{ }_{\mathrm{s} 11} \mathrm{n}-{ }_{\text {s12 }} \text { šum- }{ }_{s 14} \emptyset \\
\text { VEN-DAT-3SG.A-give-3NH.P }\end{array}$ \\
\hline
\end{tabular}

"The god Enlil has given Gutium to me."

In ex. (11) below, the ventive prefix in S4 precedes the locative2 prefix in S10, and the two morphemes form a composite dimensional prefix with a 1st ps. sg. referent. $^{22}$

(11) Lugal-zage-si 1 3:32-33 (Nippur, 23th c.)

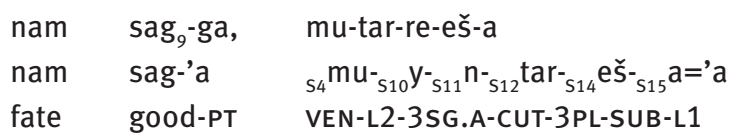

"(May they not alter) the good fate that they have determined for me."

The locative1 prefix /ni/ of S10 has no composite form, only a simple form: it always occurs without a pronominal prefix, and always refers to a 3rd ps. non-human participant. If S11 contains no morpheme and consequently the locative1 prefix forms an open, unstressed syllable, then the vowel of /ni/ becomes syncopated, and the prefix is reduced to /n/; see, for example, ex. (31) and (196) below.

The pronominal affixes of S11 and S14, and the composite and simple dimensional prefixes are not agreement markers, as they may occur either alone or may be accompanied by a coreferential noun phrase in the clause. Syntactically they must be considered anaphoric pronouns. ${ }^{23}$ They may also exceptionally occur with free pronouns, but only to express a contrast.

In the indicative mood, Sumerian finite verbal forms distinguish two verbal tenses: present-future and preterit. Sumerian has a relative tense system: the verbal form called the present-future here denotes actions that are not anterior, but simultaneous or posterior, relative to a given reference point. The verbal form called the preterit denotes actions that are anterior, relative to a given reference point. ${ }^{24}$ The opposition between the present-future and the preterit is neutralized in verbal forms

22 See Mithun (1996) for the pronominal use of morphemes with a cislocative meaning in other languages.

23 See Corbett (2003, pp. 164-192) or (2006, pp. 99-112) for a summary of the discussion on verbal prefixes which may occur either alone or may be accompanied by a coreferential noun phrase.

24 See Streck (1998). 
denoting states, as verbs used in a stative meaning always use the preterit tense. The terms present-future and preterit are kept here as convenient labels used for referring to the two tenses of Sumerian.

Formally the two tenses are distinguished either i) solely by agreement patterns involving the affixes in S11 and S14, or by a combination of i) with one of the following grammatical devices: ii) the form of the verbal stem in S12, and iii) the suffix -/ed/, a marker of present-future, in $\mathrm{S} 13 .^{25}$

In exx. (10) and (12) the same verb šum "to give" occurs in the preterit and present-future, respectively. In (10) the Agent is expressed with a pronominal prefix in S11, while in (12) it is expressed by a pronominal suffix in S14. Both the preterit and the present-future verbal forms use the same simple stem šum.

(12) Gudea Statue B 8:21-23 (Lagash, 21st c.) (P232275)

\begin{tabular}{|c|c|c|c|}
\hline $\begin{array}{l}\mathrm{u}_{3}-\mathrm{de}_{2}-\mathrm{a} \\
\text { udea }=\mathrm{e}\end{array}$ & alan-e, & $\begin{array}{l}\text { inim } \\
\text { inim=ø }\end{array}$ & $\begin{array}{l}\text { im-ma-šum }-m u \\
{ }_{s 2} \mathrm{i}-{ }_{s 4} m-{ }_{s 5} b-{ }_{s 6} a-{ }_{s 12} \check{s ̌ u m}_{s 14} \mathrm{e}\end{array}$ \\
\hline & AT.NH & word=ABS & $3 \mathrm{NH}-\mathrm{DA}$ \\
\hline
\end{tabular}

"Gudea entrusted the statue with the (following) message:"

Exx. (13)-(15) use the same verb zig "to rise, to raise”. Exx. (13) and (14) contain transitive verbal forms, which differ both in their agreement pattern (in the former the Agent is expressed with a pronominal prefix in S11, while in the latter with a pronominal suffix in S14), and in the form of the verbal stem (the former uses the simple stem zig, and the latter the partly reduplicated stem zizi). In ex. (14) both the agreement pattern and the use of the partly reduplicated stem signal the presentfuture tense.

(13) Lugal-zage-si 1 2:46-3:2 (Nippur, 23rd c.)

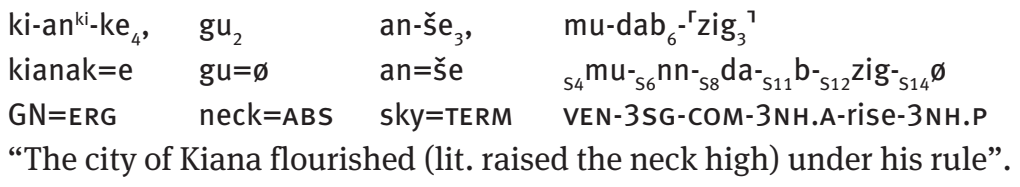

(14) Gudea Cyl. A 11:13 (Lagash, 21st c.) (ETCSL 2.1.7) (P232300)

\begin{tabular}{|c|c|c|c|}
\hline$g_{2}$ & $\mathrm{pa}_{4}-\mathrm{e}$ & $g u_{2}-b i$ & ma-ra-ab-zi-zi \\
\hline & $\mathrm{pa}=\mathrm{e}$ & $g u=b i=\varnothing$ & ${ }_{s 4} \mathrm{mu}{ }_{\mathrm{s} 6}{ }^{\mathrm{r}-}{ }_{\mathrm{s} 7} \mathrm{a}-{ }_{\mathrm{s} 11} \mathrm{~b}-{ }_{\mathrm{s} 12} \mathrm{zizi}-{ }_{\mathrm{s} 14} \mathrm{e}$ \\
\hline vee & ditch=ERG & neck $=3 \mathrm{NH} . \mathrm{POSS}=\mathrm{ABS}$ & VEN-2SG-DAT-3NH.P-rise PF-3NH.A \\
\hline
\end{tabular}

"The levees and ditches will be full to the brim for you (lit. will raise their neck for you)."

25 See Zólyomi (2007, pp. 25-28) for more details. 
Ex. (15) contains an intransitive, passive verbal form in the present-future. Its tense is marked both by its agreement pattern (the Subject is expressed with a pronominal suffix in S14) and by the presence of the /ed/ suffix in S13.

(15) Nam-mahni 712 (Lagas 21st c.)

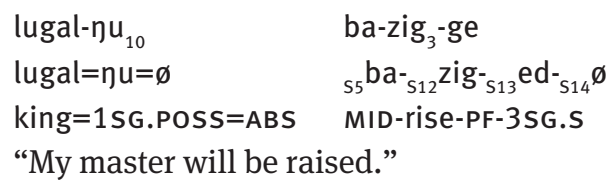

Exx. (16), which is a finite relative clause, and (17) contain the verb "to speak" in the preterit and present-future, respectively. They differ both in their agreement pattern (in the former the Agent is expressed with a pronominal prefix in S11, while in the latter with a pronominal suffix in S14), and in the form of the verbal stem (the former uses the simple stem dug, while the latter the suppletive stem e). In ex. (17) both the agreement pattern and the use of the suppletive stem signals the present-future tense.

(16) Iri-kagina 1 8:10-12 (RIME1.9.9.1) (Lagash, 24th c.)

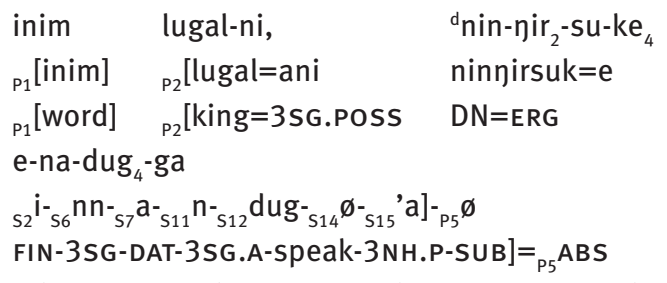

"the commands, Ningirsu, his master, gave him, ..."

(17) Nam-mahni 6 2:6 (RIME 3/1.1.12.6) (Lagash, 21st c.) (P234696)

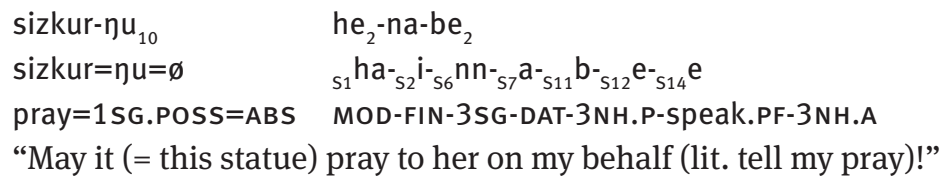

In the indicative mood finite verbs are negated with the prefix /nu/- in S1. Modality of the verbal form is marked with modal prefixes whose position is also S1. Some of the modal prefixes, including the most frequent, /ha/-, may express both epistemic and deontic modality; their meaning is partly a function of verbal form's tense. Their use is summarized in Table 1.5 below (the signs + and - stand for positive and negative modality respectively). 
Tab. 1.5: Sumerian modal prefixes

\begin{tabular}{|c|c|c|c|c|c|}
\hline \multicolumn{3}{|c|}{ epistemic } & \multicolumn{3}{|c|}{ deontic } \\
\hline \multirow[t]{2}{*}{+} & \multicolumn{2}{|c|}{-} & \multirow[t]{2}{*}{+} & \multicolumn{2}{|c|}{-} \\
\hline & weak & strong & & weak & strong \\
\hline \multirow[t]{2}{*}{ /ha/- } & $/ \mathrm{na}(\mathrm{n}) /-$ & /bara/- & /ga/-, /ha/- & /na(n)/- & /bara/ \\
\hline & & & /nuš/- & & \\
\hline \multicolumn{6}{|l|}{ /na/- } \\
\hline /ša/- & & & & & \\
\hline
\end{tabular}

In the imperative form of the verbs, the verbal stem occurs in $\mathrm{S} 1$ instead of in its usual position, S12, as in ex. (18) below, with the consequence that all verbal prefixes are positioned after a preterit stem in imperative verbal forms; see also exx. (205) and (289) below.

(18) CUSAS 17, 13 2:1 (?, cca. 23th c.) (P251599)

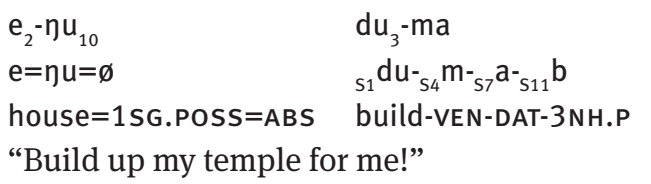

The morphology and function of non-finite verbal forms will be discussed in detail in section 4.2 below. 